\title{
ISOLATION AND CHARACTERIZATION OF A NOVEL HYALURONIDASE INHIBITOR FROM A MARINE ACTINOMYCETES STRAIN
}

\author{
Enjuro Harunari1)*, Chiaki Imada1), Yasuhiro Igarashi2), Takao Fukuda2), \\ Takeshi Terahara'), Takeshi Kobayashi') \\ 1)Graduate School, Tokyo University of Marine Science and Technology, \\ 4-5-7 Konan, Minato-ku, Tokyo 108-8477, Japan; \\ *e-Mail: enjuro.h@gmail.com \\ 2)Biotechnology Research Center, Toyama Prefectural University, \\ 5180 Kurokawa, Imizu, Toyama 939-0398, Japan
}

\begin{abstract}
A novel hyaluronidase inhibitor $(\mathrm{HI})$ was isolated from the culture extract of a marine-derived actinomycete strain. This strain MB-PO13 was isolated from ascidian (Molgula manhattensis) in Tokyo Bay. Out of about 1,000 isolates from various marine organisms, strain MB-PO1 3 had the strongest inhibitory activity and was selected for further study. The strain showed abundant-to-moderate growth on most media, forming a grayish mycelium. On the basis of the taxonomical characteristics, the strain was classified as belonging to the genus of Streptomyces and was named as Streptomyces sp. strain MB-PO13. The structure of HI was elucidated by interpretation of NMR data. HI displayed about 25 -fold potent hyaluronidase inhibitory activity against hyaluronidase than glycyrrhizin.
\end{abstract}

Keywords: marine actinomycetes; Streptomyces; hyaluronidase inhibitor

\section{INTRODUCTION}

Hyaluronidase (HAase), an endoglycosidase, hydrolyzes hyaluronic acid (HA), an only glycosaminoglycan, non-sulfated and not attached to a core protein, repeating unit of Dglucuronic acid and $\mathrm{N}$-acetyl glucosamine. HA was synthesized by HA synthases which polymerize HA on intracellular membrane surface. The HA polymers are extruded onto the glycocalyx or into the extra cellular matrix (ECM). HA exists mainly in skin, primarily in dermis in mammalian and is degraded by some different HAases in somatic cells step by step. HAase is found in various organisms: mammalians, bacteria (Streptomyces (Ohya et al. 1970), Streptococcus (Hamai et al. 1989)), bacteriophage (Baker et al. 2002), venom of terrestrial (bees (Kameny et al. 1984), hornets (Kolarich et al. 2005), scorpions (Pessini et al. 2001), snakes (Girish et al. 2006), lizards (Tu et al. 1983)) and marine (krill (Karlstam et al. 1983), lobster (Krishnapillai et al. 1999), fishes (Hopkins et al. 1998)) animals. HAase is the only acidactive enzyme in the mammalian circulation. There are three types of eukaryotic HAase; neutral-active endo- $\beta$ - $N$-glucosaminidase, acidic-active endo- $\beta-N$-glucosaminidase and endo$\beta$-glucuronidase.

Variously-sized HAs have several functions in inflammation (Noble et al. 1996; Termei et al. 2013), immunity and so on depending on the molecular size. Low molecular weight HA stimulates angiogenesis (Feinberg et al. 1983) and induction of chemokine (McKee et al. 1996) and cytokine (Kobayashi et al. 1996; Nakamura et al. 2004; Asari et al. 2010). In contrast, 
high molecular weight HA suppresses these phenomena (Termei et al. 2013; McKee et al. 1996; Delmage et al. 1986). Recently, extremely high molecular weight HA (6-1 $2 \mathrm{MDa}$ ) was found in naked mole-rat (Heterocephalus glaber) fibroblasts (Tian et al. 1996) which is over five times larger than human and mouse HA (0.5-3 MDa) (Holmes et al. 1988). Naked mole rat is known as an exceptionally long-life rat (40/86 were alive over 24 years) (Sherman et al. 2002), surprisingly, neoplasm has never been found in the rat (Sherman et al. 2002, Buffenstein et al. 2008). However, in the case of knocking down HA synthase or overexpression of HAase, tumors formation was observed (Holmes et al. 1988).

HAase is the molecular target of anti-inflammatory and anti-allergic drugs. For example, anti-allergic agents such as disodium cromoglycate (DSCG), tranilast and inflammatory agent such as glycyrrhizin show HAase inhibitory activity (Sakamoto et al. 1980; Kakegawa et al. 1983; Furuya et al. 1997). Furthermore, the compound 48/80, a histamine-releasing agent activates HAase (Kakegawa et al. 1985). Therefore, HAase inhibitors have the potential as the anti-inflammation drug.

\section{MATERIAL AND METHODS}

Strain MB-PO13 was isolated from a sea squirt (Molgula manhattensis) collected at a harbor near Minato-ku, Tokyo. The strain was identified as a member of genus Streptomyces on the basis of $99.2 \% 16$ S rRNA gene sequence identity $(1,429$ nucleotides; DDBJ accession number AB840588) with Streptomyces misawanensis strain NBRC 13855 (accession number $A B$ 184533).

Strain MB-PO13 growing on a yeast-starch agar medium consisting of soluble starch (Wako Pure Chemical Industries, Ltd.) 1.0\%, yeast extract (Difco Laboratories) $0.2 \%$, and agar $1.5 \%$ (pH 7.2) was inoculated into $500 \mathrm{~mL} \mathrm{K-1}$ flasks each containing $100 \mathrm{~mL}$ of the $\mathrm{V}$ 22 seed medium consisting of soluble starch $1.0 \%$, glucose $0.5 \%$, NZ-case (Wako Pure Chemical Industries, Ltd.) $0.3 \%$, yeast extract (Difco Laboratories) $0.2 \%$, tryptone (Difco Laboratories) $0.5 \%, \mathrm{~K} 2 \mathrm{HPO} 40.1 \%$, MgSO $4.7 \mathrm{H} 2 \mathrm{O} 0.05 \%$, and $\mathrm{CaCO} 30.3 \%$ (pH 7.0). The flasks were placed on a rotary shaker $(200 \mathrm{rpm})$ at $30^{\circ} \mathrm{C}$ for 4 days. Then, the seed culture $(3$ $\mathrm{mL}$ ) was transferred into $500 \mathrm{~mL} \mathrm{~K}-1$ flasks each containing $100 \mathrm{~mL}$ of the A-3 M production medium consisting of soluble starch $2.0 \%$, grycerol $2.0 \%$, glucose $0.5 \%$, Pharmamedia $1.5 \%$, yeast extract $0.3 \%$, and Diaion HP-20 resin (Mitsubishi Chemical Co.) $1 \%$. The pH of the medium was adjusted to 7.0 before sterilization. The inoculated flasks were placed on a rotary shaker $(200 \mathrm{rpm})$ at $30^{\circ} \mathrm{C}$ for 7 days.

After incubation, $100 \mathrm{~mL}$ of ethyl acetate was added to each flask, and the flasks were allowed to shake for one hour. The mixture was centrifuged at 6,000 rpm for $10 \mathrm{~min}$ and the organic layer was separated from the aqueous layer containing the mycelium. Evaporation of the solvent gave $450 \mathrm{mg}$ of cluded extract from $1 \mathrm{~L}$ of culture. The extract $(450 \mathrm{mg})$ was subjected to reversed-phase ODS column chromatography with a gradient of $\mathrm{MeCN} / 0.1 \%$ $\mathrm{HCO} 2 \mathrm{H}(2: 8,3: 7,4: 6,5: 5,6: 4,7: 3$, and $8: 2 \mathrm{v} / \mathrm{v})$. The fraction eluted with $70 \% \mathrm{MeCN}$ was 
pooled and evaporated in vacuo, and the remaining aqueous solution was extracted with EtOAc. The organic layer was then concentrated to give a red solid (46 mg). The final purification was achieved by preparative HPLC using a liniar gradient of MeCN/0.1\% $\mathrm{HCO} 2 \mathrm{H}$ (MeCN concentration: $15-85 \%$ for 0-30 $\mathrm{min}$ ) at $4 \mathrm{~mL} / \mathrm{min}$, yielding $\mathrm{HI}(20 \mathrm{mg})$ with a retention time of $22.5 \mathrm{~min}$.

HAase inhibitory activity was measured by turbidimetric assay described by Ferrante (Ferrante 1956) with slight modifications. HAase (EC 3.2.1.35) from bovine testes type I-S (Sigma Chemical Co.) and HA sodium salt from rooster comb (Wako Pure Chemical Industries, Ltd.) were dissolved in acetate buffer $(0.2 \mathrm{M}$ sodium acetate, $0.15 \mathrm{M} \mathrm{NaCl}, \mathrm{pH} 5.0)$. The mixtures contained the $100 \mu \mathrm{L}$ of $0.1 \%$ HAase and $20 \mu \mathrm{L}$ of samples in DMSO was incubated at $37^{\circ} \mathrm{C}$ for $20 \mathrm{~min}$. After incubation, $100 \mu \mathrm{L}$ of $1 \% \mathrm{HA}$ was added and incubated at $37^{\circ} \mathrm{C}$ for $60 \mathrm{~min}$. After incubation, the enzymatic reaction was terminated by the addition of $1 \mathrm{~mL}$ of $2.5 \%$ cetyltrimethylammonium bromide (CTAB) in $2 \%$ aqueous $\mathrm{NaOH}$ solution. The turbidity at $400 \mathrm{~nm}$ was measured after $30 \mathrm{~min}$. All incubations were carried out in triplicate.

\section{RESULTS AND DISCUSSION}

The producing strain MB-PO13 was cultured in A-3M medium at $30^{\circ} \mathrm{C}$ for seven days, and the whole culture broth was extracted with EtOAc at $\mathrm{pH} 3$. The extract was fractionated by reversed-phase column chromatography, followed by HPLC purification on a C18 column, to yield (1) as an optically active, red amorphous powder ([a]25D-168, DMSO). A molecular formula of $\mathrm{C} 3 \mathrm{OH} 21 \mathrm{NO} 13$ was confirmed by high-resolution ESITOFMS data showing a pseudomolecular ion $[M+H]+$ at $m / z$ 604.1091. The IR spectrum indicated the presence of hydroxyl (3356 cm-1) functionalities. UV spectrum showed absorption maxima at 307, 351, 368 and $506 \mathrm{~nm}$ similar to those of the rubromycin class of antibiotics (Echardt et al. 1978).

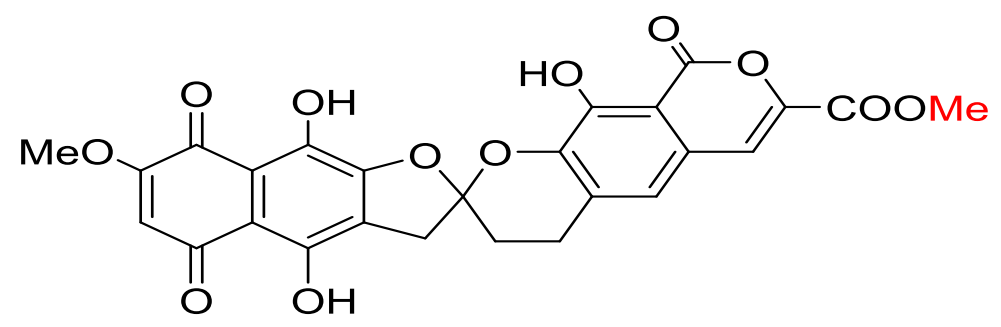

Figure 1. Y-Rubromycin structure

The $1 \mathrm{H}$ NMR spectrum of 1 measured in DMSO-d6 indicated the presence of a methoxy ( $(\mathrm{H}$ 3.89), three methine $(\delta \mathrm{H} 6.41,7.25$ and 7.52) and four exchangeable $(\delta \mathrm{H} 9.44,10.67$, 11.90 and 13.14 ) protons. In the 13 C NMR spectrum, all the 25 carbons assignable to the $y$ rubromycin core were detected. Comparison with MS data showed that 5 carbon atoms were lacking (Echardt et al. 1978). The 1H-1H COSY spectrum established only one spin system $\mathrm{H}$ $3 / \mathrm{H}-4$. Further $\mathrm{HSQC}$ and $\mathrm{HMBC}$ analysis allowed the assignment of most of the $13 \mathrm{C}$ signals except for C-9, C-8'a and C-9' (Figure 2). An exchangeable proton at $\mathrm{\delta H} 9.44$ showed a correlation to $C-11$, suggesting that this proton could be an amide proton. 


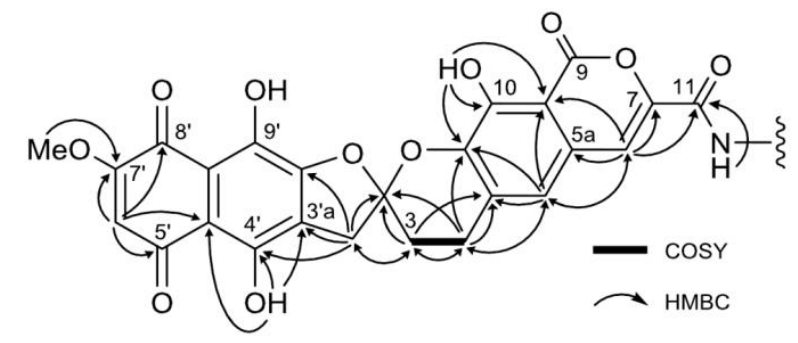

Figure 2.1 $\mathrm{H}-1 \mathrm{H}$ COSY and $\mathrm{HMBC}$ correlations of compound 1

The NMR data and UV spectrum of 1 strongly indicated the presence of Y-rubromycin skeleton, but three carbons remained to be assigned. In addition, five more carbons were not detected in the $13 \mathrm{C}$ NMR spectrum.

Table 1.NMR data for 1 in DMSO-d6

\begin{tabular}{|c|c|c|c|}
\hline \multirow[t]{2}{*}{ Position } & \multicolumn{3}{|c|}{1} \\
\hline & $\delta c^{a}$, type & $\delta \mathrm{H}$, mult. $(J \text { in Hz})^{b}$ & $\mathrm{HMBC}^{\mathrm{c}}$ \\
\hline $2\left(2^{\prime}\right)$ & $113.0, q C$ & & \\
\hline 3 & $29.1, \mathrm{CH}_{2}$ & $2.37, \mathrm{~m} ; 2.56, \mathrm{~m}$ & $2,4 a$ \\
\hline 4 & 22.7, $\mathrm{CH}_{2}$ & $3.06, \mathrm{~m} ; 3.17, \mathrm{~m}$ & $2,3,4 a, 5,10 a$ \\
\hline $4 a$ & $132.8, q C$ & & \\
\hline 5 & $119.5, \mathrm{CH}$ & $7.25, \mathrm{~s}$ & $4 a, 5 a, 6,9 a, 10 a$ \\
\hline $5 a$ & $128.9, q C$ & & \\
\hline 6 & $110.9, \mathrm{CH}$ & $7.52, \mathrm{~s}$ & $5,5 a, 7,9 a, 11$ \\
\hline 7 & 144.7, qC & & \\
\hline 9 & $164.4, q C$ & & \\
\hline $9 a$ & 107.0, qC & & \\
\hline 10 & $150.0, q C$ & & \\
\hline $10 a$ & $141.1, q C$ & & \\
\hline 11 & $158.8, q C$ & & \\
\hline $2^{\prime}(2)$ & $113.0, q C$ & & \\
\hline \multirow[t]{2}{*}{$3^{\prime}$} & $39.4, \mathrm{CH}_{2}$ & $3.55, d(18.0)$ & $3,2^{\prime}, 3^{\prime} a, 4^{\prime}, 9^{\prime} a$ \\
\hline & & $3.48, d(18.0)$ & \\
\hline $3^{\prime} a$ & 123.6, qC & & \\
\hline $4^{\prime}$ & $157.8, q C$ & & \\
\hline $4^{\prime} \mathrm{a}$ & $107.2, q C$ & & \\
\hline $5^{\prime}$ & $185.9, \mathrm{qC}$ & & \\
\hline $6^{\prime}$ & $110.9, \mathrm{CH}$ & $6.41, \mathrm{~s}$ & $4^{\prime} a, 5^{\prime}, 7^{\prime}, 8^{\prime}$ \\
\hline $7^{\prime}$ & $161.2, q C$ & & \\
\hline $8^{\prime}$ & 180.2, qC & & \\
\hline $8^{\prime} a$ & $114.0, \mathrm{qC}$ & & \\
\hline $9^{\prime}$ & $148.3, q C$ & & \\
\hline $9^{\prime} a$ & 153.7, qC & & \\
\hline 7'-OMe & 58.0, $\mathrm{CH}_{3}$ & $3.89, \mathrm{~s}$ & $7^{\prime}$ \\
\hline $10-\mathrm{OH}$ & & $10.67, \mathrm{~s}$ & $9 a, 10,10 a$ \\
\hline $4^{\prime}-\mathrm{OH}$ & & $13.14, \mathrm{~s}$ & $3^{\prime} a, 4^{\prime}, 4^{\prime} a$ \\
\hline 9'-OH & & $11.90, \mathrm{~s}$ & \\
\hline $11-\mathrm{NH}$ & & $9.44, \mathrm{~s}$ & 11 \\
\hline
\end{tabular}


The compound 1 displayed 25-fold more potent inhibitory activity against HAase from bovine testis with an IC50 value of $14 \mu \mathrm{M}$ than glycyrrhizin (IC50=340 $\mu \mathrm{M}$ ), a well-known plant terpenoid.

\section{CONCLUSION}

A novel hyaluronidase inhibitor (HI) was isolated from the culture extract of a marinederived actinomycete strain. This strain MB-PO13 was isolated from ascidian (Molgula manhattensis) in Tokyo Bay. Out of about 1,000 isolates from various marine organisms, strain MB-PO13 had the strongest inhibitory activity and was selected for further study. The strain showed abundant-to-moderate growth on most media, forming a grayish mycelium. On the basis of the taxonomical characteristics, the strain was classified as belonging to the genus of Streptomyces and was named as Streptomyces sp. strain MB-PO13. The structure of HI was elucidated by interpretation of NMR data. HI (1), a new member of rubromycin family antibiotics, was isolated from marine-derived actinomycete strain Streptomyces sp. as a HAase inhibitor. HI (1) displayed 25-fold more potent inhibitory activity against HAase than glycyrrhizin, a well-known plant terpenoid. This finding may provide valuable information for developing a drug design for anti-inflammation agents.

\section{Acknowledgments}

We wish to thank the laboratory members for their advice and help.

\section{REFERENCES}

Asari, A.; Kanemitsu, T.; Kurihara, H. Oral administration of high molecular weight hyaluronan $(900 \mathrm{kDa})$ controls immune system via toll-like receptor 4 in the intestinal epithelium. J. Biol. Chem. 2010, 285, 24751-24758.

Baker, J.R.; Dong, S.; Pritchard, D.G. The hyaluronan lyase of Streptococcus pyogenes bacteriophage H4489A. Biochem. J. 2002, 365, 317-322.

Buffenstein, R. Neglible senescence in the longest living rodent, the naked mole-rat: insights from a successfully aging species. J. Comp. Physiol. B. 2008, 178, 439-445.

Delmage, J.M.; Powars, D.R.; Jaynes, P.K.; Allerton, S.E.; The selective suppression of immunogenicity by hyaluronic acid. Ann.Clin. Lab. Sci. 1986, 16, 303-310.

Feinberg, R.N.; Beebe, D.C. Hyaluronate in vasculogenesis. Science, 1983, 220, $1177-1179$.

Furuya, T.; Yamagata, S.; Shimoyama, Y.; Fujihara, M.; Morishita, N.; Ohtsuki, K. Biochemical characterization of glycyrrhizin as an effective inhibitor for hyaluronidase from bovine testis. Biol. Pharm. Bull. 1997, 20, 973-977.

Girish, K.S.; Kemparaju, K. Inhibition of Najanaja venom hyaluronidase: Role in the management of poisonous bite. Life Sciences, 2006, 78, 1433-1440.

Hamai, A.; Morikawa, K.; Horei, K.; Tokuyasu, K. Purification and characterization of hyaluronidase from Streptococcus dysgalactiae. Agric. Biol. Chem. 1989, 53, $2163-$ 2168.

Holmes, M.W.; Bayliss, M.T.; Muir, H. Hyaluronic acid in human articular cartilage. Age-related changes in content and size. Biochem. J. 1988, 250, 435-441.

Hopkins, B.J.; Hodgson, W.C. Enzyme and biochemical studies of stonefish (Synacnejatrachynis) and solidfish (Gymnapistesmarmoratus)Toxicon, 1998, 36, 791-793.

Kakegawa, H.; Mitsuo, N.; Matsumoto, H.; Satoh, H.; Akagi, M.; Tasaka, K. Hyaluronidaseinhibitory and anti-allergic activities of the photo-irradiated products of tranilast.Pharm. Bul. 1983, 33, 3738-3744. 
Kakegawa, H.; Matsumoto, H.; Satho, T.Activation of hyaluronidase by metallic salts and compound $48 / 80$, and inhibitory effect of anti-allergic agents on hyaluronidase. Chem. Pharm. Bar. 1985, 33, 642-646.

Kemeny, D.M.; Dalton, N.; Lawrence, A.J.; Pearce, F.L.; Vernon, C.A. The purification and characterisation of hyaluronidase from the venom of the honey bee, Apismellifera. Eur. J. Biochem., 1984, 139, 217-223.

Kolarich, D.; Léonard, R.; Hemmer, W.; Altmann, F. The N-glycans of yellow jacket venom hyaluronidases and the protein sequence of its major isoform in Vespula vulgaris. FEBS J.2005, 272, 5182-5190.

Karlstam, B.; Liungloef, A. Purification and partial characterization of a novel hyaluronic aciddegrading enzyme from Antarctic krill (Euphausiasuperba). Polar Biol.1991, 11, 501507.

Krishnapillai, A.M.; Taylor, K.D.A.; Morris, A.E.J.; Quantick, P.C. Characterisation of Norway lobster (Nephropsnorvegicus) hyaluronidase and comparison with sheep and bovine testicular hyaluronidase. Food Chem.1999, 65, 515-521.

Kobayashi, H.; Terao, T. Am. J. Physiol. Cell Physiol. 1997, 273, 1151-1159.

McKee, C.M.; Penno, M.B.; Cowman, M.; Burdick, M.D.; Strieter, R.M.; Bao, C.; Noble, P.W. Hyaluronan (HA) fragments induce chemokine gene expression in alveolar macrophages. The role of HA size and CD44. J. Clin. Invest. 1996, 98, 2403-2413.

Nakamura, K.; Yokohama, S.; Yoneda, M.; Okamoto, S.; Tamaki, Y.; Ito, T.; Okada, M.; Aso, K.; Aso, K.; Makino, I. High, but not low, molecular weight hyaluronan prevents T-cellmediated liver injury by reducing proinflammatory cytokines in mice. J. Gastroenterol., 2004, 39, 346-354.

Noble, P.W.; McKee, C.M.; Cowman, M.; Shin, H.S. Hyaluronan fragments activate an NFkappa B/I-kappa B alpha autoregulatory loop in murine macrophages. J. Exp. Med. 1996, 183, 2373-2378.

Pessini, A.C.; Takao, T.T.; Cavalheiro, E.C.; Vichnewski, W.; Sampaio, S.V.; Giglio, J.R.; Arantes, E.C. A hyaluronidase from Tityusserrulatus scorpion venom: isolation, characterization and inhibition by flavonoids. Toxicon, 2001, 39, 1495-1504.

Tu, A.T.; Hendon, R.R.; Comp.Biochem. Physiol. B.Characterization of lizard venom hyaluronidase and evidence for its action as a spreading factor.1983, 76, 377-383.

Sakamoto, K.; Nagai, Hiroichi.;Koda, Akihide, K.Role of hyaluronidase in immediate hypersensitivity reaction.Immunopharmacology, 1980, 2, 139-146.

Sherman, P.W.; Javis, J.U.M. Extraordinary life spans of naked mole-rats (Heterocephalusglaber)J. Zool. 2002, 258, 307-311.

Termei, R.; Laschinger, C.; Lee, W.; McCulloch, C.A. Intercellular interactions between mast cells and fibroblasts promote pro-inflammatory signaling. Exp. Cell. Res. 2013, 319, 18391851.

Tian, X.; Azpurua, J.; Hine, C.; Vaidya, A.; Myakishev-Rempel, M.; Ablaeva, J.; Mao. Z.; Nevo, E.; Gorbunova, V.; Seluanov, A. High-molecular-mass hyaluronan mediates the cancer resistance of the naked mole rat. Nature, 2013, 499, 346-349. 